\title{
Process analytical approaches for the coil-to-globule transition of poly( $N$-isopropylacrylamide) in a concentrated aqueous suspension
}

\author{
Peter Werner $^{1} \cdot$ Marvin Münzberg ${ }^{1} \cdot$ Roland Hass $^{1} \cdot$ Oliver Reich $^{1}$
}

Received: 31 August 2016/Revised: 14 October 2016 / Accepted: 21 October 2016 /Published online: 9 November 2016

(C) The Author(s) 2016. This article is published with open access at Springerlink.com

\begin{abstract}
The coil-to-globule transition of $\operatorname{poly}(\mathrm{N}$ isopropylacrylamide) (PNIPAM) microgel particles suspended in water has been investigated in situ as a function of heating and cooling rate with four optical process analytical technologies (PAT), sensitive to structural changes of the polymer. Photon Density Wave (PDW) spectroscopy, Focused Beam Reflectance Measurements (FBRM), turbidity measurements, and Particle Vision Microscope (PVM) measurements are found to be powerful tools for the monitoring of the temperature-dependent transition of such thermo-responsive polymers. These in-line technologies allow for monitoring of either the reduced scattering coefficient and the absorption coefficient, the chord length distribution, the reflected intensities, or the relative backscatter index via in-process imaging, respectively. Varying heating and cooling rates result in ratedependent lower critical solution temperatures (LCST), with different impact of cooling and heating. Particularly, the data obtained by PDW spectroscopy can be used to estimate the thermodynamic transition temperature of PNIPAM for infinitesimal heating or cooling rates. In addition, an inverse hysteresis and a reversible building of micrometer-sized agglomerates are observed for the PNIPAM transition process.
\end{abstract}

Published in the topical collection Process Analytics in Science and Industry with guest editor Rudolf W. Kessler.

Electronic supplementary material The online version of this article (doi:10.1007/s00216-016-0050-7) contains supplementary material, which is available to authorized users.

Peter Werner

pwerner@uni-potsdam.de

1 Physical Chemistry - innoFSPEC, University of Potsdam, Am Mühlenberg 3, 14476 Potsdam-Golm, Germany
Keywords Poly $(N$-isopropylacrylamide $) \cdot$ Photon Density Wave spectroscopy · Focused Beam Reflectance Measurement · Turbidity measurement · Particle Vision Microscope measurement · Rate-dependent lower critical solution temperature

\section{Introduction}

As a typical member of sensitive or "smart" polymers, poly ( $N$-isopropylacrylamide) (PNIPAM) is one of the most frequently investigated polymers within recent decades because of its distinct thermo-sensitive behavior [1-6]. PNIPAM microgel particles exhibit a reversible coil-toglobule transition in aqueous suspensions, induced by a small temperature variation around the polymer's lower critical solution temperature (LCST). During heating, the swollen polymer microgel particle undergoes a process of changing hydrophilicity at the LCST, inducing a release of water and a compression of the polymer microgel particle. The LCST of PNIPAM is found at approximately $32{ }^{\circ} \mathrm{C}$ and thus is close to the human body temperature. Owing to the special thermoresponsive properties of PNIPAM and related materials, its potential for biological and chemical applications has been investigated intensively, for example for drug delivery [7-11], protein separation [12, 13], biosensors [14], or catalyst carriers $[15,16]$.

The LCST is a fundamental parameter of all temperaturesensitive polymers for the application in chemistry, biology, or material science. For the effective use of PNIPAM-based materials, the adjustment of the LCST to a certain temperature for a specific application is a challenging endeavor. The LCST is affected by many conditions, for example the morphology of the polymer [17], the macromolecular weight and structure as well as environmental factors such as $\mathrm{pH}$, ionic strength [18], 
and solvent type. It has been shown that the LCST of PNIPAM can be significantly shifted by copolymerization with hydrophilic or hydrophobic monomers such as styrene [19], acrylic acid [20], and others [21].

The LCST can be determined by various analytical methods like optical techniques (e.g., UV-Vis spectroscopy [20-22], dynamic and static light scattering [22-27], infrared spectroscopy [28-31], Raman spectroscopy [32], fluorescence spectroscopy [33]), differential scanning calorimetry [34], or viscometry [35]. However, many of these approaches are usually limited to rather dilute suspensions, exhibiting only single light scattering. In order to access the underlying structural changes within the polymer in its typical environment (i.e., in concentrations typically used for synthesis), further process analytical technologies (PAT), suitable for highly turbid liquids and providing high temporal resolution, are required [36]. Such methods would also be applicable to the synthesis process itself [37]. In this study, the probe-based (fiber)optical technologies Photon Density Wave (PDW) spectroscopy [38-41], Focused Beam Reflectance Measurement (FBRM) [42-45], Particle Vision Microscope (PVM) measurement [46-48], and turbidity measurement [49-51] are applied to study the LCST of aqueous PNIPAM suspensions and additionally its heating and cooling rate dependency.

\section{Background}

\section{PNIPAM coil-to-globule transition}

Aqueous PNIPAM suspensions exhibit a reversible coil-toglobule transition at a specific temperature, the so-called lower critical solution temperature (LCST). At this temperature, the PNIPAM particles undergo a structural change. In literature, different mechanisms of the coil-to-globule transition process of PNIPAM are described [28, 31, 52]. In principle, the mechanism is based on a change of hydrophilicity of the polymer. At temperatures below the LCST, the polymer exhibits an enhanced solubility in water. In this temperature range, each polymer chain is surrounded by water molecules. Near the LCST, the hydrophilicity of the polymer starts to decrease, resulting in a release of water molecules and a compression of the whole polymer network. This causes a change of refractive index during the coil-to-globule transition. During the inverse process (cooling to a temperature below the LCST), the hydrophilicity of the polymer increases again, resulting in an uptake of water molecules and an expansion of the polymer network. Concerning a single PNIPAM particle, the compression and expansion result in a decrease or increase of particle size during the coil-to-globule or globule-to-coil transition process, respectively. It is well known that the coil-toglobule transition exhibits a hysteresis between the heating and cooling period. Depending on the applied investigation method, here the coil-to-globule transition is described to happen mostly at higher temperatures than the globule-to-coil transition process [28].

\section{Photon Density Wave spectroscopy}

PDW spectroscopy is a PAT to quantitatively and independently characterize the absorption and scattering properties of highly turbid liquid suspensions [53, 54]. The absorption coefficient $\mu_{\mathrm{a}}$ and the reduced scattering coefficient $\mu_{\mathrm{s}}$ ' are related to the concentration of the light absorbing material and the characteristics of the scatters (e.g., their concentration, size, and refractive index but also their inner particle structure [55]), respectively. In consequence, based on the reduced scattering coefficient, PDW spectroscopy can be used for in-line particle sizing in the size regime of approximately $50 \mathrm{~nm}$ to $500 \mu \mathrm{m}[38,53]$. PDW spectroscopy is based on photon transport theory in multiple light scattering systems [56]. It operates in the frequency domain, i.e., the emitted light, creating the PDW inside the multiply light scattering liquid, is intensity modulated with different frequencies. From the dependence of the PDW on the modulation frequency and the distance between emission and detection fiber, the absorption and reduced scattering coefficients are determined independently. In contrast to many other optical technologies, PDW spectroscopy is capable of quantifying the optical properties of the material under investigation at volume fractions of the disperse phase well above $30 \%$.

\section{Focused Beam Reflectance Measurement}

Focused Beam Reflectance Measurement (FBRM) is a PAT to analyze particle dimensions and particle numbers in liquid suspensions. It is based on the reflectance of a focused laser beam, scanning across the dispersed particles close to the optical probe. Obtained data include the so-called chord length distribution, being sensitive to changes of the particle number and dimension. FBRM is one of the very few in-line probe-based methods for particle characterization in concentrated systems.

\section{Particle Vision Microscope measurements}

PVM is a probe-based in-line microscope, applied to directly visualize suspended structures (e.g., particles, droplets, or cells) within a process. The instrument can be operated in reflection or transflection mode. In addition, a relative backscatter index $(R B I)$ can be obtained. The $R B I$ is an area-based turbidity signal, deduced from the obtained images. 


\section{Turbidity measurements}

Probe-based turbidity measurements exist in various experimental setups, e.g., reflection, transmission (optical density, OD), or transflection geometries are found. Typically, detected light intensities at a wavelength of $860 \mathrm{~nm}$ are related to incident light intensities. For quantitative results, especially when comparing to other experimental setups, turbidity measurements require calibration [57].

\section{Materials and methods}

\section{Chemicals}

The monomer $N$-isopropylacrylamide (NIPAM, $97 \%$, SigmaAldrich Chemie GmbH, Taufkirchen, Germany) was recrystallized in $n$-hexane (95\%, Sigma-Aldrich Chemie $\mathrm{GmbH}$, Taufkirchen, Germany) and dried for $24 \mathrm{~h}$ before use. The monomer styrene ( $\geq 99 \%$ Sigma-Aldrich Chemie $\mathrm{GmbH}$, Taufkirchen, Germany) was filtered over aluminum oxide (Carl Roth $\mathrm{GmbH}+\mathrm{Co}$. KG, Karlsruhe, Germany) to remove the stabilizer. The crosslinker $N, N$-methylenebisacrylamide (BIS, biology grade, AppliChem GmbH, Darmstadt, Germany), the initiator potassium peroxodisulfate (KPS, 99.0 \%, Carl Roth GmbH + Co. KG, Karlsruhe, Germany), the buffer disodium phosphate dodecahydrate $(\geq 98 \%$, Carl Roth GmbH + Co. KG, Karlsruhe, Germany), and the emulsifier sodium lauryl sulfate (SDS, $99.5 \%$, Carl Roth GmbH + Co. KG, Karlsruhe, Germany) were used as received. Ultrapure water (Milli-Q-Integral system, Merck KGaA, Darmstadt, Germany) was used in all experiments.

\section{Synthesis of PNIPAM microgel particles}

PNIPAM microgel particles were synthesized by free radical precipitation polymerization in aqueous environment according to the formulation in [58-60]. Briefly, $500 \mathrm{~mL}$ deionized water was purged with nitrogen under stirring (100 rpm) for $60 \mathrm{~min}$ in an automated $1 \mathrm{~L}$ lab reactor (OptiMax, Mettler Toldeo GmbH, Gießen, Germany). Both the monomer (NIPAM) (110 mmol) and the crosslinker $(0.11 \mathrm{mmol})$ were added and dissolved. The solution was further purged with nitrogen for $30 \mathrm{~min}$ to exclude oxygen, followed by heatingup to $70{ }^{\circ} \mathrm{C}$. An amount of $2.78 \mathrm{mmol}$ of KPS was dissolved in $30 \mathrm{~mL}$ deionized water and then injected into the reactor to start the reaction. The polymerization was performed under reflux for $4 \mathrm{~h}$ at $70{ }^{\circ} \mathrm{C}$. The polymer suspension was cooled down and stored at room temperature, without further purification. The solid content of the polymer was determined by gravimetry (HR83 Halogen, Mettler Toledo GmbH, Gießen, Germany) to $2.37 \%(w / w)$ (conversion $96 \%$ ).

\section{Synthesis of polystyrene particles}

Polystyrene (PS) particles were synthesized by free radical emulsion polymerization in aqueous environment. Briefly, $480 \mathrm{~mL}$ deionized water was purged with nitrogen under stirring $(300 \mathrm{rpm})$ for $90 \mathrm{~min}$ in an automated $1 \mathrm{~L}$ lab reactor (OptiMax, Mettler Toldeo GmbH, Gießen, Germany). The emulsifier $(4.3 \mathrm{mmol})$ and the buffer $(0.84 \mathrm{mmol})$ were dissolved in $50 \mathrm{~mL}$ deionized water. Both the monomer (908 mmol) and the solution of the emulsifier and the buffer were added into the reactor. The solution was further purged with nitrogen for $60 \mathrm{~min}$ to exclude oxygen, followed by heating-up to $55^{\circ} \mathrm{C}$ at a heating rate of $1.16 \mathrm{~K} \mathrm{~min}^{-1}$. A total of $3.55 \mathrm{mmol}$ of KPS was dissolved in $4 \mathrm{~mL}$ deionized water and then injected into the reactor to start the reaction. The polymerization was performed under reflux for $17 \mathrm{~h}$ at $55^{\circ} \mathrm{C}$. The polymer suspension was cooled down and stored at room temperature. The solid content of the polymer was determined by gravimetry (HR83 Halogen, Mettler Toledo $\mathrm{GmbH}$, Gießen, Germany) to $12.54 \%(w / w)$ (conversion $74 \%$, hydrodynamic diameter $\left(d_{\mathrm{h}}\right)$ of $110.8 \mathrm{~nm}$ (z-average)). For the reference experiments, the PS suspension was diluted with deionized water to $1.34 \%(w / w)$.

\section{Temperature cycling of polymer suspensions}

The aqueous PNIPAM suspension, as obtained from the synthesis, was heated and cooled inside the automated lab reactor under stirring $(100 \mathrm{rpm})$ in the range from 25 to $40{ }^{\circ} \mathrm{C}$ with ten different rates in the range of $0.1-1 \mathrm{~K} \mathrm{~min}^{-1}$. Temperature equilibration at $25^{\circ} \mathrm{C}$ as well as at $40{ }^{\circ} \mathrm{C}$ was performed for $20 \mathrm{~min}$. During the experiment, the temperature inside the reactor $\vartheta_{\mathrm{r}}$ and in the reactor jacket $\vartheta_{\mathrm{j}}$ was measured. For the temperature control, the reactor temperature $\vartheta_{\mathrm{r}}$ was used. From the difference between the reactor and jacket temperature $\vartheta_{\mathrm{r}}-\vartheta_{\mathrm{j}}$, thermal information is obtained. All temperature cycles were performed for three times in random order. Temperature, PVM measurements, turbidity measurements, PDW spectroscopy, and FBRM were performed simultaneously inside the reactor. Correlation of FBRM, PVM, PDW spectroscopy, and turbidity data with the temperature information of the reactor was provided by self designed software (LabView2011, National Instruments GmbH, München, Germany), assigning a temperature value to the temporal value of an experimental data point (time index provided by the individual instrument software). For PDW spectroscopy, the temporal midpoint of a single measurement was used.

It has to be stressed that the control software of the reactor (iControl 5.2.219 SP1, Mettler Toledo GmbH, Gießen, Germany) is in theory capable of correlating imported data with temperature information. However, the software version 5.2.219 SP1 contains a fundamental bug, resulting in 
misleading correlation information (see Electronic Supplementary Material (ESM) Fig. S1).

\section{PDW spectroscopy}

The PDW spectrometer is a self-built instrument described in detail elsewhere [61]. Conditions for the PDW experiments were set as follows: emission wavelength of $515 \mathrm{~nm}$, distances between detection fiber and emission fiber of $10-18 \mathrm{~mm}$ in 11 steps, intensity modulation frequencies of $10-610 \mathrm{MHz}$ in 41 steps. As the refractive index of PNIPAM could not be determined experimentally, for data analysis [38], the refractive index of PMMA, typical for polymers, was used instead. The refractive index of the suspension is calculated [53] using the refractive indices of pure water $\left(n_{\text {water }}=1.3355,[62]\right)$ and PMMA $\left(n_{\mathrm{PMMA}}=1.4949\right.$ [63]) at $515 \mathrm{~nm}$, the solid content of $2.37 \%$ of the polymer, and the densities of water $\left(\rho_{\text {water }}=\right.$ $0.997075[62])$ and the polymer $\left(\rho_{\text {PMMA }}=1.18[64]\right)$, resulting in a refractive index of the PNIPAM suspension of $n_{\text {suspension }}=1.3391$ at $515 \mathrm{~nm}$. For data analysis of the PS suspension, a refractive index of $n_{\text {suspension }}=1.3493$ was used $\left(n_{\mathrm{PS}}=1.6012\right.$ [63], solid content of $1.34 \%$, density $\rho_{\mathrm{PS}}=$ 1.055 [64]). Due to the unknown exact value of the refractive index of PNIPAM, the obtained optical coefficients are therefore only estimates. However, any changes in the optical coefficients should be related to structural or chemical variations. The temporal resolution was approximately $1 \mathrm{~min}^{-1}$. The self-built PDW spectrometer operates well above $\mu_{\mathrm{s}}{ }^{\prime} \approx$ $0.05 \mathrm{~mm}^{-1}$ [57].

\section{Focused Beam Reflectance Measurement}

The FBRM was performed using a $19 \mathrm{~mm}$ probe at $75 \mathrm{~Hz}$ (ParticleTrack G400, Mettler Toledo GmbH, Gießen, Germany). Raw data were analyzed applying the "Primary" chord length selection model of the software iC FBRM (Mettler Toledo GmbH, Gießen, Germany). For the particle size analysis, two different chord length fractions were chosen. The first one was chosen for small particles in the range below $50 \mu \mathrm{m} N_{<50 \mu \mathrm{m}}$ and the second one for larger particles in the range from 50 to $1000 \mu \mathrm{m} N_{50-1000 \mu \mathrm{m}}$. The temporal resolution was approximately $5 \mathrm{~min}^{-1}$. The lower detection limit for chord lengths is specified as $0.5 \mu \mathrm{m}$ by the supplier.

\section{Particle Vision Microscope measurements}

PVM measurements were performed using a $19 \mathrm{~mm}$ probe in reflection geometry with a temporal resolution of approximately $30 \mathrm{~min}^{-1}$ (V819, Mettler Toledo GmbH, Gießen, Germany). The optical resolution, i.e., differentiation of objects, is specified by the manufacturer as larger than $2 \mu \mathrm{m}$. The relative backscatter index $R B I$, describing the relative relation between detected and incident light, was calculated by the software iC PVM (Mettler Toledo GmbH, Gießen, Germany). This parameter can be understood as an areabased turbidity information and is not necessarily limited by the optical resolution given above.

\section{Turbidity measurements}

The turbidity measurements were performed with a fiberoptical turbidity probe (inPro8200, Mettler Toledo GmbH, Gießen, Germany) in combination with a spectrometer (MCS600 with light source CLD 600, detectors MCS 621 and MCS 611, Carl Zeiss AG, Jena Gemany). The relative intensity $I_{\mathrm{R}}$ at a wavelength of $860 \mathrm{~nm}$ in reflection mode was used for turbidity analysis. The temporal resolution was approximately $7 \mathrm{~min}^{-1}$.

\section{Results and discussion}

Figure 1 shows the reduced scattering coefficient $\mu_{\mathrm{s}}$, the absorption coefficient $\mu_{\mathrm{a}}$, the FBRM counts $N_{<50 \mu \mathrm{m}}$, the FBRM counts $N_{50-1000 \mu \mathrm{m}}$, the relative backscatter index $R B I$, the reflected intensity from turbidity $I_{\mathrm{R}}$, the temperature $\vartheta_{\mathrm{r}}$, and the temperature difference $\vartheta_{\mathrm{r}}-\vartheta_{\mathrm{j}}$ as function of time for one temperature cycle of the PNIPAM suspension with a heating and cooling rate of $0.3 \mathrm{~K} \mathrm{~min}^{-1}$. All applied techniques exhibit signal changes during the heating and cooling cycle of the PNIPAM suspension, especially around the LCST of PNIPAM (for heating at approximately 25-40 $\mathrm{min}$ and for cooling at approximately $100-115 \mathrm{~min}$ ). At the equilibration temperature $\left(25\right.$ and $\left.40{ }^{\circ} \mathrm{C}\right)$, most of the signals are constant. This indicates that each of the used techniques is suitable to investigate the coil-to-globule transition of highly concentrated PNIPAM particle suspensions. The temperature difference $\vartheta_{\mathrm{r}}-\vartheta_{\mathrm{j}}$ exhibits a short endothermic peak during the heating period (at approximately $35 \mathrm{~min}$ ) and a short exothermic peak during the cooling period (at approximately $110 \mathrm{~min}$ ). Therefore, energy consumption and release are limited to a short time period during heating and cooling, respectively. In contrast, these peaks were not observed for the PS suspensions. Hence, it could be supposed that these peaks are connected to the structural changes of PNIPAM. All further peaks of $\vartheta_{\mathrm{r}}-\vartheta_{\mathrm{j}}$ result simply from the proportional-integral-derivative (PID) controller during discontinuous temperature changes.

\section{Coil-to-globule transition of PNIPAM monitored with different techniques}

\section{PDW spectroscopy}

To obtain specific information about the coil-to-globule transition process of PNIPAM, the signals of the different 
Fig. 1 Reduced scattering coefficient $\mu_{\mathrm{s}}$ ' (circle), absorption coefficient $\mu_{\mathrm{a}}$ (square), FBRM counts $N_{<50 \mu \mathrm{m}}$ (triangle), FBRM counts $N_{50-1000 \mu \mathrm{m}}$ (diamond), relative backscatter index $R B I$ (hexagon), reflected intensity from turbidity $I_{\mathrm{R}}$ (star), temperature $\vartheta_{\mathrm{r}}$ (solid line) and temperature difference $\vartheta_{\mathrm{r}}-\vartheta_{\mathrm{j}}$ (dashed line) as function of time for the PNIPAM suspension (heating and cooling rate of $0.3 \mathrm{~K} \mathrm{~min}^{-1}$ ). A-F indicate points in time at which PVM pictures in Fig. 4 were taken

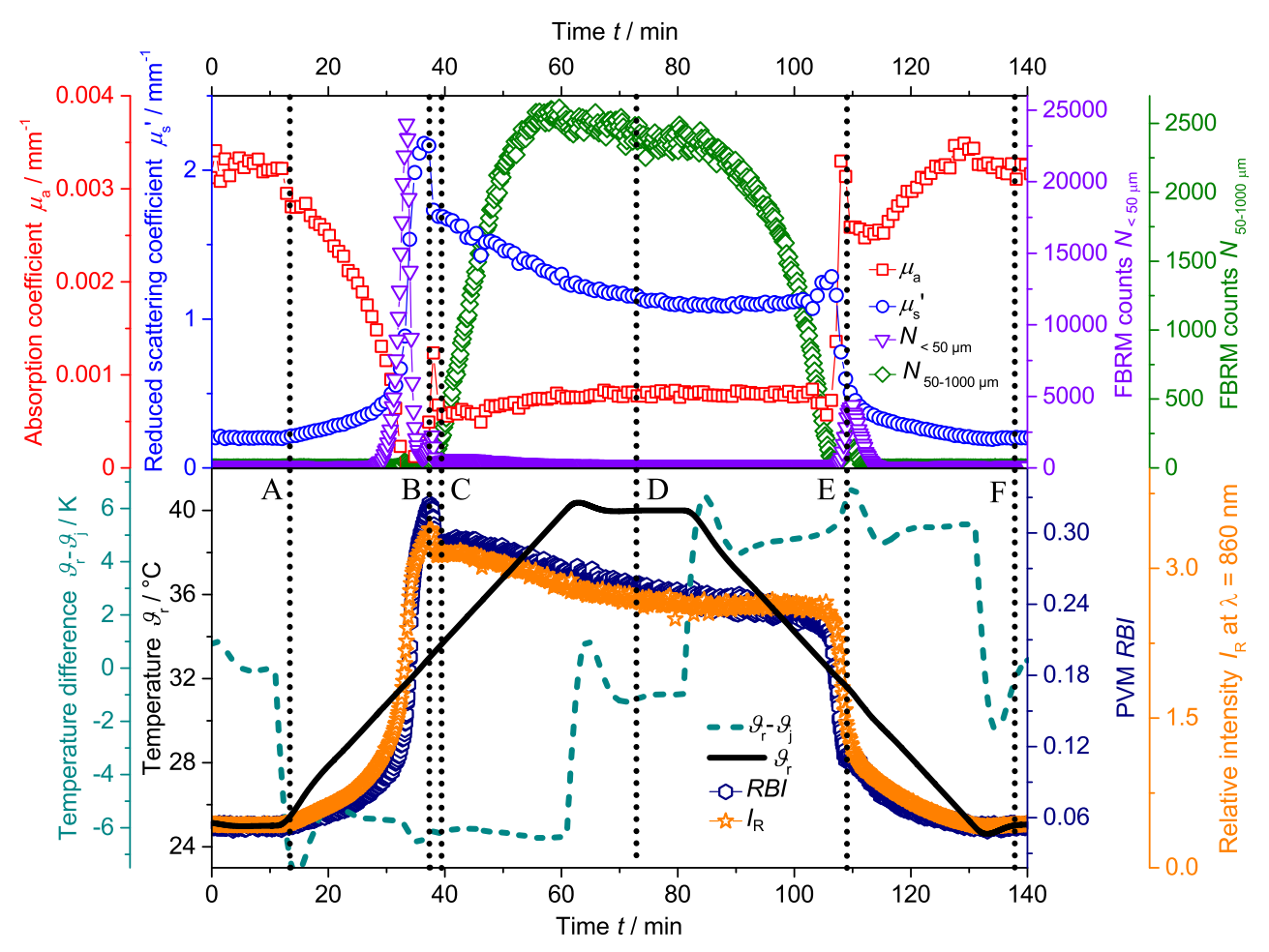

techniques were plotted against the reactor temperature. Figure 2 displays the absorption and the reduced scattering coefficient of the PNIPAM suspension and the aqueous PS suspension as a function of reactor temperature. Three repeating cycles with a cooling and heating rate of $0.2 \mathrm{~K} \mathrm{~min}^{-1}$ are shown. In case of the PS suspension, no changes of the optical coefficients are observed during the temperature treatment. PS, being a non-thermo-responsive polymer, is expected to undergo no structural changes during the heating or cooling process. Hence, no changes of the optical coefficients are

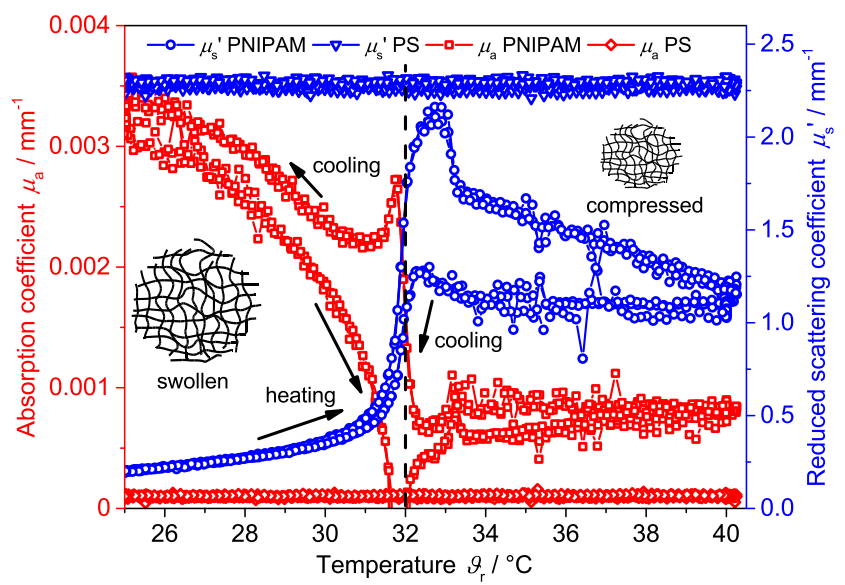

Fig. 2 Reduced scattering coefficient $\mu_{\mathrm{s}}$ ' and absorption coefficient $\mu_{\mathrm{a}}$ measured by PDW spectroscopy at $515 \mathrm{~nm}$ of the PNIPAM suspension ( $\mu_{\mathrm{s}}$ ' (circle), $\mu_{\mathrm{a}}$ (square)) and of the PS suspension ( $\mu_{\mathrm{s}}$ ' (triangle), $\mu_{\mathrm{a}}$ $($ diamond) $)$ as a function of reactor temperature $\vartheta_{\mathrm{r}}$ (heating and cooling rate of $0.2 \mathrm{~K} \mathrm{~min}^{-1}, 3$ temperature cycles). Dashed line represents the typical literature value for the LCST of PNIPAM anticipated. Inversely, if changes in the optical coefficients are observed for a thermo-responsive polymer like PNIPAM by PDW spectroscopy, these are most likely due to structural changes of the polymer and are no artifacts of the measurement technology. In case of the PNIPAM suspension, strong changes of $\mu_{\mathrm{s}}$ ' and $\mu_{\mathrm{a}}$ are observed. At the beginning of the heating period, in the range from 25 to $31^{\circ} \mathrm{C}$, the reduced scattering coefficient increases from $0.22 \mathrm{~mm}^{-1}$ to approximately $0.47 \mathrm{~mm}^{-1}$. The reduced scattering coefficient shows a steep increase (to approximately $2.1 \mathrm{~mm}^{-1}$ ) in the temperature range from 31 to $33^{\circ} \mathrm{C}$. Above this temperature range, the reduced scattering coefficient decreases rapidly to approximately $1.7 \mathrm{~mm}^{-1}$ within a temperature difference of $0.5^{\circ} \mathrm{C}$, followed by a continuous decrease to approximately $1.2 \mathrm{~mm}^{-1}$ at $40{ }^{\circ} \mathrm{C}$. During cooling to a temperature of $33^{\circ} \mathrm{C}$, the reduced scattering coefficient remains constant. Subsequently, after a short increase around the LCST, $\mu_{\mathrm{s}}$ ' decreases rapidly to its initial value at $25^{\circ} \mathrm{C}$. In contrast, during heating, a strong decrease in $\mu_{\mathrm{a}}$ is observed already below the LCST. At approximately $32{ }^{\circ} \mathrm{C}$, slightly negative values are determined being unphysical and hence are measurement artifacts. Nonetheless, after the transition of PNIPAM at the LCST, $\mu_{\mathrm{a}}$ quickly equilibrates to approximately $0.610^{-3} \mathrm{~mm}^{-1}$ and remains nearly constant up to $40^{\circ} \mathrm{C}$. During the cooling period, $\mu_{\mathrm{a}}$ again remains constant until the LCST is reached, followed by a steep increase to approximately $2.710^{-3} \mathrm{~mm}^{-1}$. Below the LCST, the absorption coefficient increases again to its initial value at $25^{\circ} \mathrm{C}$. Comparing the experimental values for $\mu_{\mathrm{a}}$ at 25 and $40^{\circ} \mathrm{C}$, a change of a factor of approximately 
4 is observed. The changes of $\mu_{\mathrm{s}}$ ' and $\mu_{\mathrm{a}}$ are believed to be related to the water being removed from the polymer (resulting additionally in a change of refractive index) and to the structural changes of the polymer network when the temperature approaches the LCST. Accordingly, the absorption and the reduced scattering coefficient are potential indicators for the dehydration or hydration status of the PNIPAM particles. As the two optical coefficients are affected differently during heating and cooling, they might be linked to different steps of the coil-to-globule and globule-to-coil transition process. The reproducibility of the two optical coefficients over several heating and cooling cycles indicates that the coil-toglobule and globule-to-coil process of the PNIPAM particles is reversible. The whole transition process of PNIPAM has different impacts on the values of $\mu_{\mathrm{s}}$ ' and $\mu_{\mathrm{a}}$. Both the absorption and the reduced scattering coefficients exhibit a hysteresis. To the best of our knowledge, the effect of an inverted hysteresis, as detected by PDW spectroscopy, seems to be no experimental artifact, even though the temporal resolution of the PDW spectrometer limits data quality for the higher heating and cooling rates. The inverted hysteresis has been observed only rarely in literature with other experimental techniques [31]. More often, ordinary hystereses have been described [28, 58, 65-67]. At the moment, the underlying mechanism, i.e., the coil-to-globule transition, being responsible for the inverted hysteresis is still not understood.

\section{PVM und turbidity measurements}

In Fig. 3, the relative intensity $I_{\mathrm{R}}$ of the turbidity measurements and the relative backscatter index $R B I$ measured by PVM is displayed as a function of temperature. Three

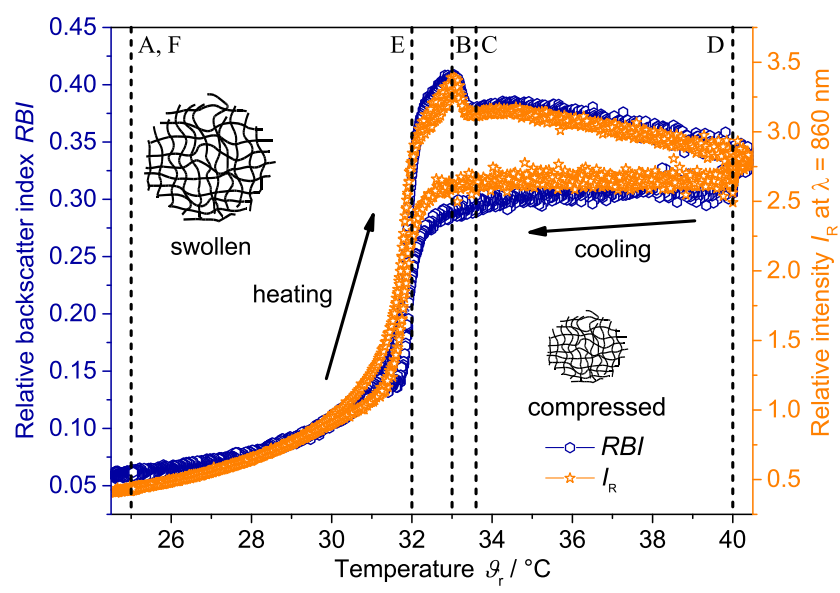

Fig. 3 Relative intensity $I_{\mathrm{R}}$ (star) from turbidity measurements and the relative backscatter index $R B I$ (hexagon) measured by PVM as a function of temperature (heating and cooling rate of $0.3 \mathrm{~K} \mathrm{~min}^{-1}, 3$ temperature cycles for turbidity measurement, 1 temperature cycle for PVM measurements)

repeating cycles with a cooling and heating rate of $0.3 \mathrm{~K} \mathrm{~min}^{-1}$ for the turbidity measurements and one cycle for PVM measurements (for clearer data visibility) are shown. The relative intensity $I_{\mathrm{R}}$ of the turbidity probe exhibits a similar trend as the RBI of the PVM. In both cases, a continuous increase during heating $\left(25-32^{\circ} \mathrm{C}\right)$, followed by a sharp drop at approximately $33{ }^{\circ} \mathrm{C}$ is observed. Subsequently, both signals decrease slightly until a temperature of approximately $40{ }^{\circ} \mathrm{C}$ is reached. During the cooling period, both trends exhibit nearly constant values $\left(40-33^{\circ} \mathrm{C}\right)$ until the LCST is reached, followed by a sharp decrease $\left(33-31^{\circ} \mathrm{C}\right)$, and a leveling off to the initial values. Both trends show an inverse
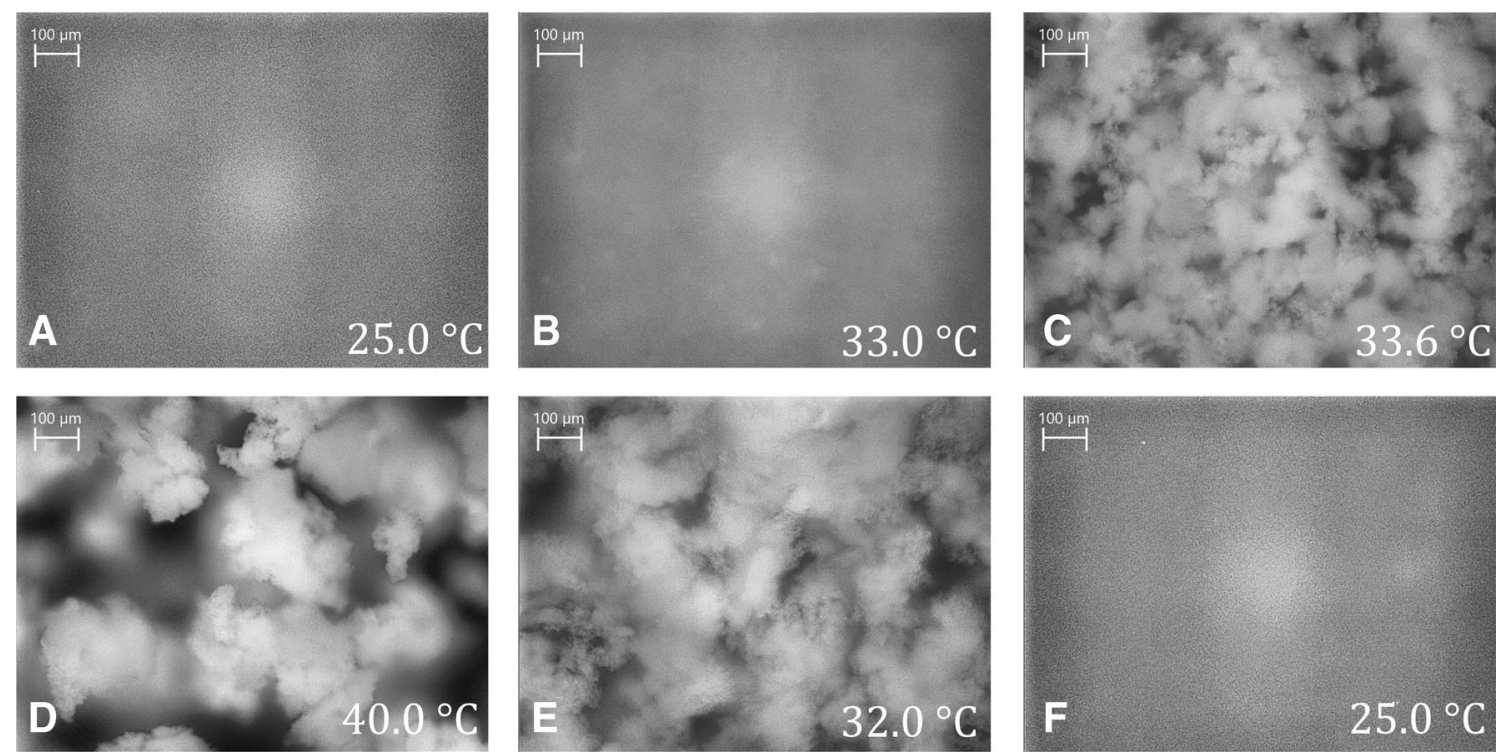

Fig. 4 PVM images at specific temperatures (time points A-F, as indicated in Figs. 1, 3 and 5) of the PNIPAM suspension with a rate of $0.3 \mathrm{~K}$ min ${ }^{-1}$ 
hysteresis during the temperature period in accordance to the PDW spectroscopy measurements.

For a better understanding of the observed signal changes, corresponding PVM images at significant points in time are shown in Fig. 4 (cf. Fig. 1 for temporal position). At the beginning of the heating period $\left(\mathrm{A}\right.$, at $\left.25^{\circ} \mathrm{C}\right)$, no structures can be resolved, indicating that the polymer network exhibits no structures in the micrometer regime. The bright spots represent the irradiating light of the PVM probe. Also image B ( $33{ }^{\circ} \mathrm{C}$, at the maximum value of the $R B I$ trend), taken above the LCST during the heating process, shows no structures in the micrometer regime. Surprisingly, only shortly afterwards $\left(\mathrm{C}\right.$, at $\left.33.6{ }^{\circ} \mathrm{C}\right)$ structures with a floc-like appearance in the size of approximately $100 \mu \mathrm{m}$ are visible. With increasing temperature, the size of the agglomerates increases to approximately $250 \mu \mathrm{m}\left(\mathrm{D}\right.$, at $\left.40{ }^{\circ} \mathrm{C}\right)$. During cooling, the agglomerates disintegrate again $\left(\mathrm{E}\right.$, at $\left.32{ }^{\circ} \mathrm{C}\right)$, reforming structures at $25^{\circ} \mathrm{C}(\mathrm{F})$, which cannot be resolved by the PVM. The detected agglomeration of the PNIPAM particles to these large agglomerates during the heating period therefore seems to be completely reversible. It has been reported that such an agglomeration effect can be induced by adding salt or nonadsorbing polymers [68-70]. In this study, however, the agglomeration occurs without addition of any further substances. Since no purification (e.g., dialysis) of the suspension has been performed, it remains unclear if any residual reactant influences the aggregation step. Before the first and after the last temperature cycle, a STEM image was taken (cf. ESM Fig. S2). In both STEM images, separated non-aggregated particles were visible. No differences were observed, underlying the thesis of a reversible transition process.

Deducing from the PVM images, signal changes of the $R B I$ and the relative intensity in the temperature range above $32^{\circ} \mathrm{C}$ are probably due to the building of micrometer sized objects. Signal changes below $32{ }^{\circ} \mathrm{C}$ are therefore due to processes in the nanometer regime. Here, the sharp increase of the $R B I$ and the relative intensity in the range from 30 to $33^{\circ} \mathrm{C}$ is believed to display the particle shrinking during the coil-to-globule transition. The release of the water molecules and compression of the polymer result in an increase of the refractive index. This causes stronger scattering and increases the values of the $R B I$ and the $I_{\mathrm{R}}$ as well as simultaneously the reduced scattering coefficient (cf. Fig. 1). Above $33^{\circ} \mathrm{C}$, all three trends exhibit a decrease up to a temperature of $33.6^{\circ} \mathrm{C}$. From PVM images, it can be deduced that the PNIPAM particles start to form larger structures in this temperature range. With increasing temperature, agglomerates are forming with a size of approximately $250 \mu \mathrm{m}$. During the cooling period $\left(40-32{ }^{\circ} \mathrm{C}\right)$, the size of the agglomerates decreases again followed by a complete disintegration. The sharp decrease of the three trends (cf. Figs. 2 and 3 ) is due to the incorporation of the water molecules into the polymer network and hence the swelling of the PNIPAM particles. At $25{ }^{\circ} \mathrm{C}$, no micrometer-sized structures are observed any more.

\section{Focused Beam Reflectance Measurements}

In Fig. 5, the FBRM counts $N_{<50 \mu \mathrm{m}}$ and $N_{50-1000 \mu \mathrm{m}}$ are displayed as a function of temperature. For better data visibility, only one heating and cooling cycle with a rate of $0.3 \mathrm{~K} \mathrm{~min}^{-1}$ is shown. The impact of the coil-to-globule transition on the two FBRM counts is completely different. During the heating period, the number of counts for the small particle fraction (FBRM counts $N_{<50 \mu \mathrm{m}}$ ) increases temporarily to a maximum at approximately $31.7^{\circ} \mathrm{C}$ followed by a decrease back to the initial value at approximately $32.5^{\circ} \mathrm{C}$. Only then the number of counts for the larger particle fraction (FBRM counts $N_{50-1000 \mu \mathrm{m}}$ ) increases continuously, leveling off at higher temperatures. During the cooling period, the FBRM trends exhibit a similar but inverse behavior except that the larger particle fraction shows a small number of counts at approximately $31.5^{\circ} \mathrm{C}$. The trend for the smaller particle fraction exhibits a less pronounced peak during the cooling period.

Regarding the absence of indications for micrometer sized objects in the literature, no changes in FBRM trends were expected. However, the FBRM counts $N_{<50}$ um indicate an agglomeration of the particles below the LCST (30.5$32.5^{\circ} \mathrm{C}$ ). At $33{ }^{\circ} \mathrm{C}$, these structures start to build agglomerates visible in the larger particle fraction $N_{50-1000 \mu \mathrm{m}}$ and in the PVM images C-E. FBRM counts increase in the larger particle fraction up to a temperature of $40^{\circ} \mathrm{C}$. During cooling, the agglomerates in the larger particle fraction disintegrate again (40-32 ${ }^{\circ} \mathrm{C}$ ). Interestingly, at $32{ }^{\circ} \mathrm{C}$, nearly no counts in the smaller as well as in the larger particle fraction are detected even though the PVM image E displays clearly PNIPAM

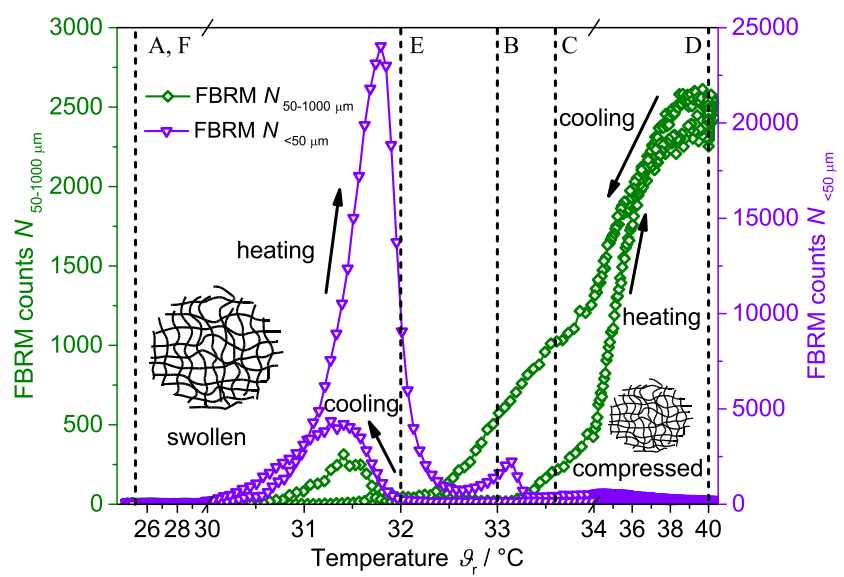

Fig. 5 FBRM counts $N_{<50 \mu \mathrm{m}}$ (triangle) and $N_{50-1000 \mu \mathrm{m}}$ (diamond) as a function of temperature (heating and cooling rate $0.3 \mathrm{~K} \mathrm{~min}^{-1}, 1$ temperature cycle) 
agglomerates in the micrometer regime. It is unclear why the FBRM cannot detect these structures. Potentially, the scattering of these agglomerates at $32{ }^{\circ} \mathrm{C}$ is too weak.

The applied PAT differ by their detection limit with respect to the minimal particle size. The relative intensity, the $R B I$, and the reduced scattering coefficient are probably suitable to detect the coil-to-globule transition in the nanometer regime as well as the agglomeration process in the micrometer regime. With an optical resolution of $2 \mu \mathrm{m}$, the PVM images on the contrary allow for a structural understanding of the micrometer-scaled agglomerates. For the FBRM, in-depth investigations need to reveal the meaning of the signal trends around the LCST. However, for all PAT, the experimental findings may represent a superposition of nano particle compression and subsequent agglomeration.

In conclusion, all techniques are suitable to detect the coilto-globule transition of PNIPAM particles and their agglomeration. Significant changes at specific temperatures are observed, which are probably induced by the change of hydrophilicity of the particles. These changes already occur below and extend above the LCST and represent an inverse hysteresis except for FBRM. From the PVM images, an agglomeration effect of the particles during the transition process is found. However, this process is completely reversible and does not change the size of the individual PNIPAM particles.

\section{Investigation of agglomerate building}

To investigate if the (de-)agglomeration during the heating and cooling cycle is a rate depending effect, the heating rate was reduced to a value of $0.01 \mathrm{~K} \mathrm{~min}^{-1}$. In Fig. 6, the reduced scattering coefficient $\mu_{\mathrm{s}}$ ', the absorption coefficient $\mu_{\mathrm{a}}$, the FBRM counts $N_{<50 \mu \mathrm{m}}$, the FBRM counts $N_{50-1000 \mu \mathrm{m}}$, the relative backscatter index $R B I$, the temperature difference $\vartheta_{\mathrm{r}}-\vartheta_{\mathrm{j}}$, and the temperature $\vartheta_{\mathrm{r}}$ are displayed as function of time. Figure 7 displays the corresponding PVM images at certain temperatures. The heating period starts at $20^{\circ} \mathrm{C}$ with a rate of $0.5 \mathrm{~K} \mathrm{~min}^{-1}$. At $30^{\circ} \mathrm{C}$, the system is heated with a slower rate of $0.01 \mathrm{~K} \mathrm{~min}^{-1}$ until the temperature reaches a value of $34^{\circ} \mathrm{C}$, followed by a heating rate of $0.5 \mathrm{~K} \mathrm{~min}^{-1}$ until the system reaches a temperature of $40{ }^{\circ} \mathrm{C}$. The system is held at $40{ }^{\circ} \mathrm{C}$ for $20 \mathrm{~min}$ followed by a cooling period of $0.1 \mathrm{~K} \mathrm{~min}^{-1}$ until the temperature reaches the initial value of $20^{\circ} \mathrm{C}$.

All trends of the different techniques in Fig. 6 are similar to the trends in Fig. 1. However, for several techniques, a sharp signal change during the change of heating rate from 0.01 to $0.1 \mathrm{~K} \mathrm{~min}^{-1}$ is detected. In detail, the temperature difference $\vartheta_{\mathrm{r}-} \vartheta_{\mathrm{j}}$ exhibits an intensive peak resulting from the PID controller of the reactor. Around the LCST, no endothermic peak is detected. The reduced scattering coefficient $\mu_{\mathrm{s}}$ ' and the relative backscatter index $R B I$ exhibit a signal decrease at the change of the heating rate. Additionally, the number of counts of the FBRM $N_{50-1000 \mu \mathrm{m}}$ increases.

During heating, no structures are clearly visible in the PVM images $\mathrm{G}, \mathrm{H}$, and I even though $N_{<50 \mu \mathrm{m}}$ and the $R B I$ exhibit maxima at approximately $200 \mathrm{~min}\left(\mathrm{G}, 31.7^{\circ} \mathrm{C}\right)$ and $320 \mathrm{~min}$ (I, $32.9^{\circ} \mathrm{C}$ ), respectively. At approximately $328 \mathrm{~min}(\mathrm{~J}$, $33.4^{\circ} \mathrm{C}$ ), the PNIPAM particles start to form larger structures of approximately $20 \mu \mathrm{m}$. At the same time, the FBRM counts $N_{<50 \mu \mathrm{m}}$ show a small local maximum. The size of these structures increases with rising temperature (up to image L). Comparing Figs. 4 and 7, the agglomeration process seems to
Fig. 6 Reduced scattering coefficient $\mu_{\mathrm{s}}$ ' (circle), absorption coefficient $\mu_{\mathrm{a}}$ (square), FBRM counts $N_{<50 \text { um }}$ (triangle), FBRM counts $N_{50-1000 \mu \mathrm{m}}$ (diamond), relative backscatter index $R B I$ (hexagon), temperature difference $\vartheta_{\mathrm{r}-} \vartheta_{\mathrm{j}}$ (dashed line) and temperature $\vartheta_{\mathrm{r}}$ (line) as function of time for the PNIPAM suspension (heating rate of $0.5 \mathrm{~K} \mathrm{~min}^{-1}$ in the temperature range from 20 to $30^{\circ} \mathrm{C}$, heating rate of $0.01 \mathrm{~K} \mathrm{~min}^{-1}$ in the temperature range from 30 to $34{ }^{\circ} \mathrm{C}$, heating rate of $0.5 \mathrm{~K} \mathrm{~min}^{-1}$ in the range from 34 to $40{ }^{\circ} \mathrm{C}$, cooling rate $0.1 \mathrm{~K} \mathrm{~min}^{-1}$ ). Points G-L indicate points in time at which PVM images were taken (cf. Fig. 7)

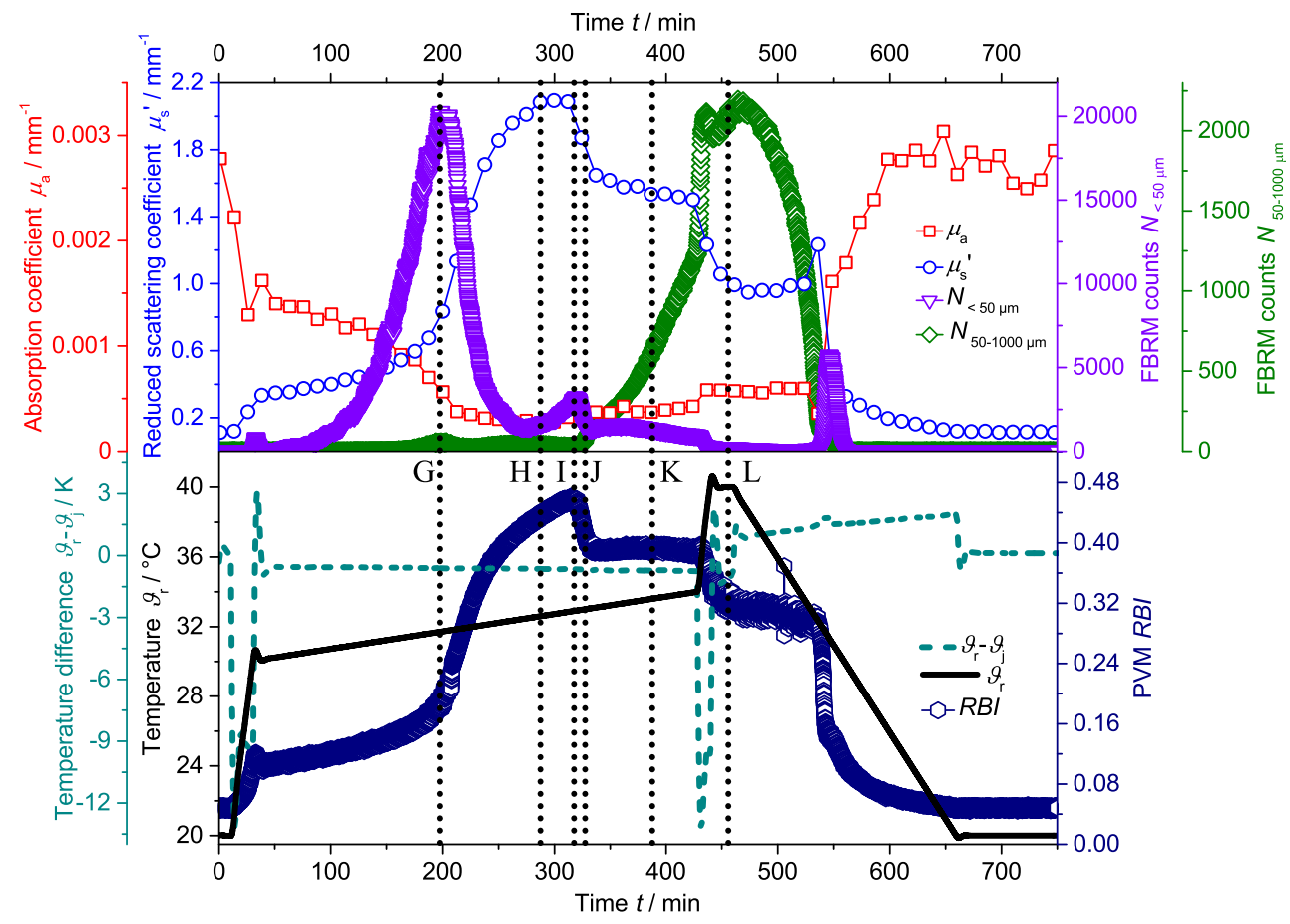



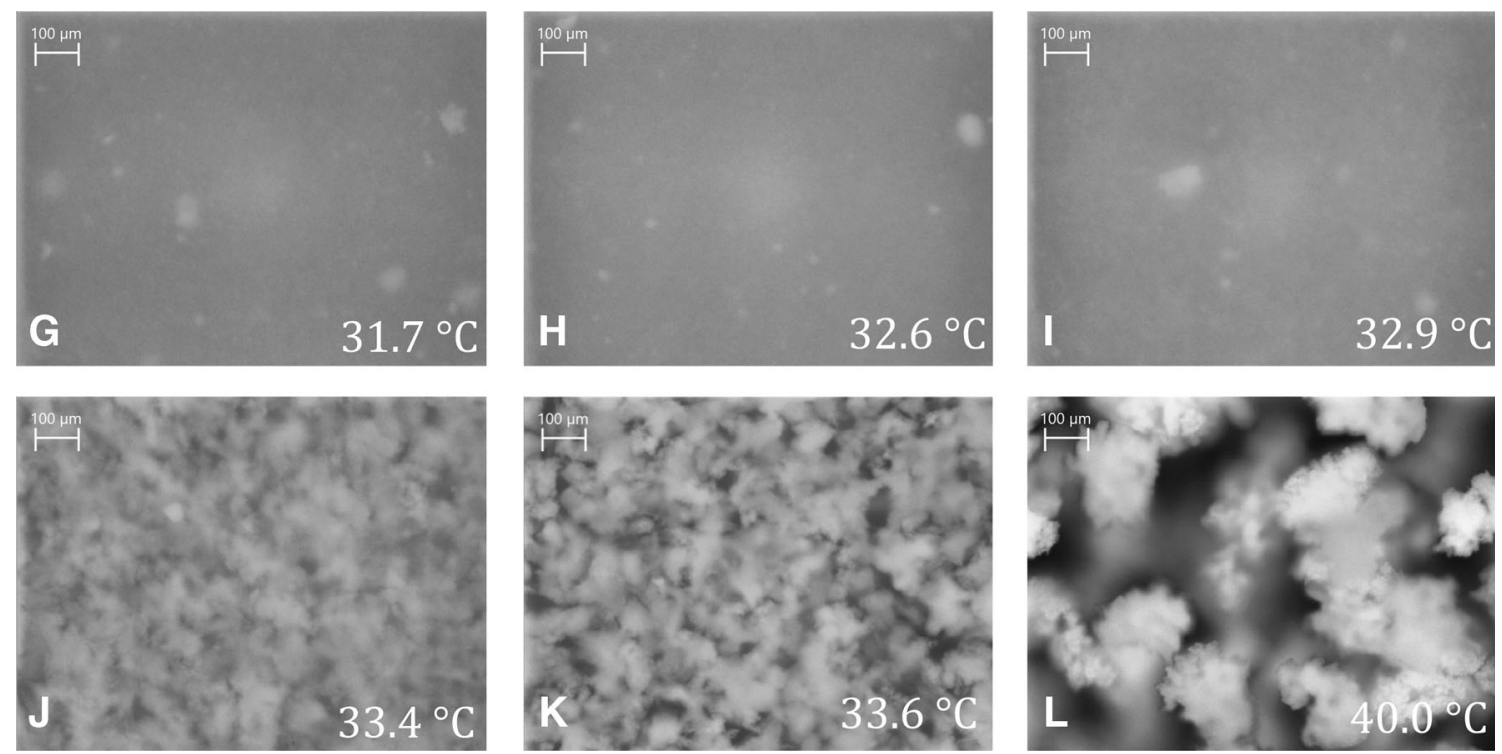

Fig. 7 PVM images at specific temperatures (G-L, as indicated in Fig. 6) during heating and cooling (heating rate of $0.5 \mathrm{~K} \mathrm{~min}^{-1}$ in the temperature range from 20 to $30{ }^{\circ} \mathrm{C}$, heating rate of $0.01 \mathrm{~K} \mathrm{~min}^{-1}$ in the temperature range from 30 to $34{ }^{\circ} \mathrm{C}$, heating rate of $0.5 \mathrm{~K} \mathrm{~min}^{-1}$ in the range from 34 to $40^{\circ} \mathrm{C}$, cooling rate $0.1 \mathrm{~K} \mathrm{~min}^{-1}$ )

$[33,58]$, the transition process of PNIPAM also has a direct influence on the absorption properties. Here, changes of the absorption coefficient are already observed at temperatures of approximately $25^{\circ} \mathrm{C}$ during heating as well as during cooling. The maximum (cooling period) increases with higher rate. Hence, the rate dependency of the absorption coefficient suggests a rate controlled hydration or dehydration of the polymer network.

\section{Rate-dependent PVM measurements}

the heating and cooling rates were systematically varied in the range from 0.1 to $1.0 \mathrm{~K} \mathrm{~min}^{-1}$ and randomly repeated three times for each rate. Besides a systematic evaluation of the kinetic behavior, such a variation could allow for the determination of a thermodynamic transition temperature of thermoresponsive suspensions.

\section{Rate-dependent PDW spectroscopy}

In the following, the rate-dependent behavior of changes of PNIPAM will be discussed for each technology. For PDW spectroscopy, this effect is displayed in Fig. 8. The rates were modified between 0.1 and $1.0 \mathrm{~K} \mathrm{~min}^{-1}$ in steps of $0.1 \mathrm{~K} \mathrm{~min}^{-1}$. All cycles were repeated in random order three times (only certain rates are shown for a better data visibility). The increase (heating) and decrease (cooling) of the reduced scattering coefficient is shifted in temperature and represents an inverse hysteresis.

Figure 9 displays the absorption coefficient as function of temperature, obtained in parallel to the reduced scattering coefficient (cf. Fig. 8). As has been observed also in other studies PVM measurements. Each temperature cycle was repeated randomly three times. Figure 10 displays the $R B I$ as a function of temperature with different heating and cooling rates. For better data visibility, the region around the LCST is enlarged. Additionally, only distinct rates and one cycle per rate are displayed. All rates show an increase already below the LCST. The observed hystereses are inverted and slightly broaden with increasing rate.

\section{Rate-dependent turbidity measurements}

The rate influence on the hysteresis is also observed for the turbidity measurements of the PNIPAM particles during the heating and cooling period. Figure 11 displays the relative intensity $I_{\mathrm{R}}$ at $860 \mathrm{~nm}$ as a function of temperature at different heating and cooling rates. For a clearer data visibility, only data for certain rates are displayed. The turbidity trends are similar to the $R B I$ trends. Both signals exhibit a steep increase (heating) and decrease (cooling) around the LCST. The
A rate influence on the hysteresis is also observed for the 


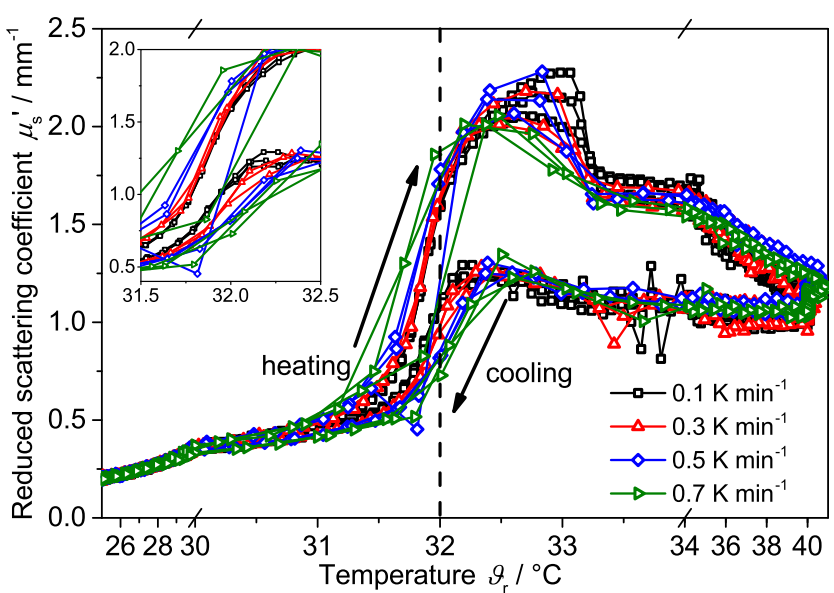

Fig. 8 Reduced scattering coefficient $\mu_{\mathrm{s}}$ ' of the PNIPAM suspension as a function of temperature at different heating and cooling rates $(3$ cycles per rate). Inlay: Temperature region between 31 and $32{ }^{\circ} \mathrm{C}$ in detail. Dashed line represents the typical literature value for the LCST of PNIPAM

developed hysteresis exhibits an inverted behavior and a slight broadening with higher rates. The maximum lies at approximately $33{ }^{\circ} \mathrm{C}$ for both measurement techniques.

\section{Rate dependence of $\vartheta_{80}$}

The influence of the heating and cooling rate on the hysteresis, as observed by PDW spectroscopy, PVM, and turbidity measurements, shows an interesting effect. For a quantitative comparison, the following definition is used: The minimum and maximum of the signal for the cooling cycle with the lowest rate $\left(0.1 \mathrm{~K} \mathrm{~min}^{-1}\right)$ is determined for each technique. The temperatures $\vartheta_{80}$ are then defined as those points where the heating and cooling cycles reach a value of $80 \%$ between these minima and maxima (OriginPro 2016G, OriginLab Corporation, Northampton, USA). $\vartheta_{80}$ has been selected due

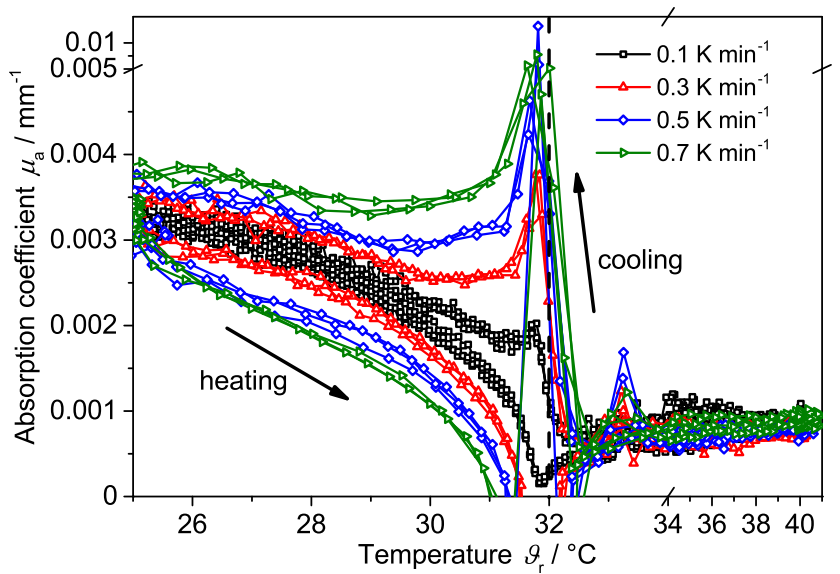

Fig. 9 Absorption coefficient $\mu_{\mathrm{a}}$ of the PNIPAM suspension as a function of temperature at different heating and cooling rates (3 cycles per rate). Dashed line represents the typical literature value for the LCST of PNIPAM

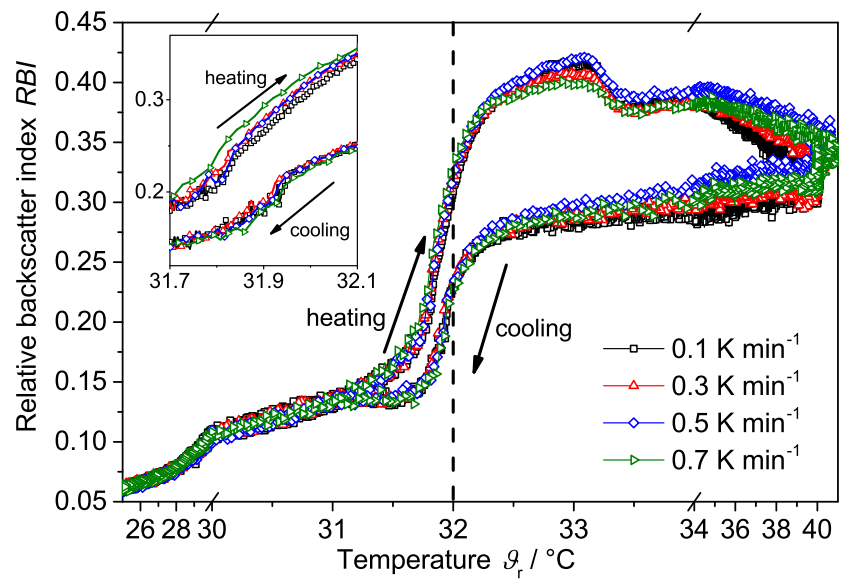

Fig. 10 Relative backscatter index $R B I$ of the PNIPAM suspension as a function of temperature at different heating and cooling rates ( 1 cycle per rate). Dashed line represents the typical literature value for the LCST of PNIPAM

to a missing analytical fit function describing all complex experimental trends. The chosen value allows for quantitative comparison of the width of the hysteresis around the LCST, across all applied PAT. In Fig. 12, the temperature $\vartheta_{80}$ is plotted as function of heating and cooling rate. A linear relationship is found for all techniques. The bigger slopes for the heating processes compared to the cooling processes signify a stronger influence of the heating rate on $\vartheta_{80}$.

Direct comparison of the different techniques indicates that PDW spectroscopy is more sensitive to structural changes (steeper slopes cf. Table 1, intercept for a rate of $0 \mathrm{~K} \mathrm{~min}^{-1}$ cf. Fig. 12) than PVM and turbidity. For a rate close to $0 \mathrm{~K} \mathrm{~min}{ }^{-1}$, the temperature $\vartheta_{80}$ is linearly extrapolated to $(31.9 \pm 0.1)^{\circ} \mathrm{C}$ (maximum error). This value at infinitely small rates could represent the thermodynamic transition temperature between the swollen and the compressed state. For a

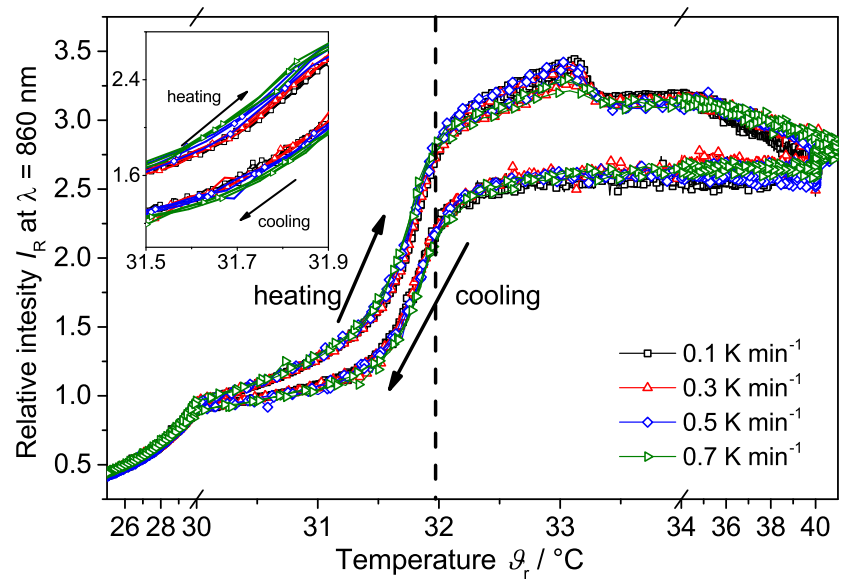

Fig. 11 Relative intensity at $860 \mathrm{~nm} I_{\mathrm{R}}$ of the PNIPAM suspension as a function of temperature at different heating and cooling rates ( 3 cycles per rate). Dashed line represents the typical literature value for the LCST of PNIPAM 


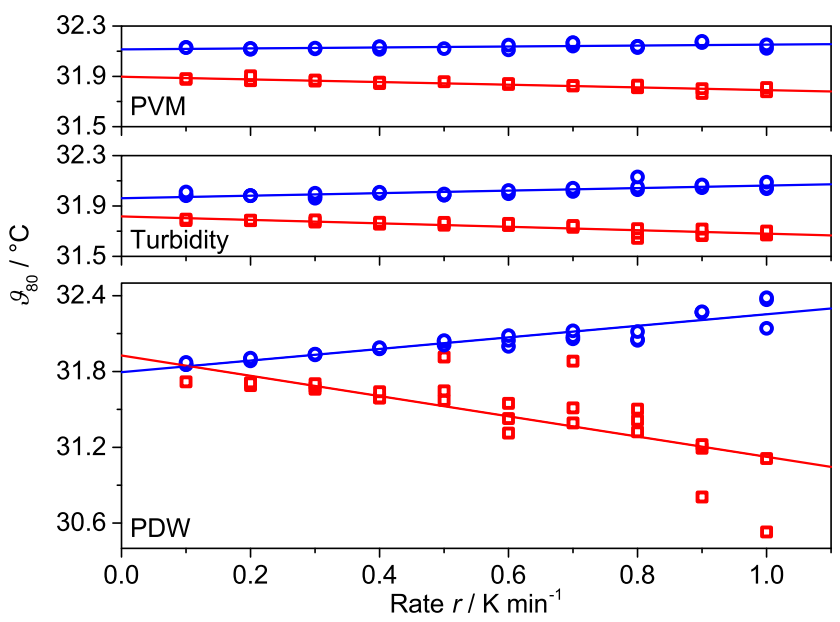

Fig. $12 \vartheta_{80}$ as a function of heating (square) and cooling (circle) rate based on the RBI value from PVM measurements (upper graph), the relative intensity $I_{\mathrm{R}}$ from the turbidity probe (middle graph), and the reduced scattering coefficient $\mu_{\mathrm{s}}$ ' from PDW spectroscopy (lower graph) for the PNIPAM suspension (3 cycles per rate). Corresponding slopes and intercepts of the linear fits are given in Table 1

higher accuracy, rates below $0.1 \mathrm{~K} \mathrm{~min}^{-1}$ would be interesting to investigate.

\section{Conclusion}

Particle Vision Microscope (PVM) measurements, turbidity measurements, Photon Density Wave (PDW) spectroscopy, and Focused Beam Reflectance Measurement (FBRM) have been used as process analytical technologies (PAT) to investigate a concentrated aqueous poly ( $N$-isopropylacrylamide) (PNIPAM) suspension during its temperature-induced transition process. As a function of heating and cooling rate, the relative backscatter index $R B I$, the relative intensity at a wavelength of $860 \mathrm{~nm} I_{\mathrm{R}}$, the absorption and the reduced scattering coefficient $\mu_{\mathrm{a}}$ and $\mu_{\mathrm{s}}{ }^{\prime}$ at $515 \mathrm{~nm}$, respectively, as well as the FBRM counts $N_{<50 \mu \mathrm{m}}$ and $N_{50-1000 \mu \mathrm{m}}$ reveal new insights into the transition process of PNIPAM. For all applied techniques, significant changes are found even noticeably below and above the lower

Table 1 Intercepts and slopes with their respective standard errors of the linear fits as shown in Fig. 12

\begin{tabular}{lllr}
\hline Method & Process & Intercept $/{ }^{\circ} \mathrm{C}$ & \multicolumn{1}{c}{ Slope $/ \mathrm{min}$} \\
\hline PVM & Cooling & $32.11 \pm 0.01$ & $0.04 \pm 0.01$ \\
& Heating & $31.90 \pm 0.01$ & $-0.11 \pm 0.01$ \\
\multirow{2}{*}{ Turbidity } & Cooling & $31.96 \pm 0.01$ & $0.10 \pm 0.02$ \\
& Heating & $31.82 \pm 0.01$ & $-0.14 \pm 0.01$ \\
PDW & Cooling & $31.79 \pm 0.02$ & $0.46 \pm 0.04$ \\
& Heating & $31.93 \pm 0.08$ & $-0.80 \pm 0.14$ \\
\hline
\end{tabular}

critical solution temperature (LCST). In particular, an inverse hysteresis is observed by PVM, turbidity measurements, and PDW spectroscopy, which has been described only rarely in literature. Additionally, a heating and cooling rate dependency has been observed by all PAT. Here, PDW spectroscopy detects the strongest effects. A thermodynamic transition temperature for the thermo-responsive polymer could be estimated to (31.9 $\pm 0.1)^{\circ} \mathrm{C}$ by PDW spectroscopy. In conjunction with the change of the absorption coefficient below the LCST, especially PDW spectroscopy may give rise to an increased understanding of the chemical and structural changes during transition processes of thermo-responsive materials in suspension. Furthermore, a fully reversible, clearly temperature-dependent agglomerate formation, which has not been induced by the addition of chemicals, was observed. The agglomerate dimension scales up to several hundreds of micrometers, as e.g. is visualized by the PVM. In addition to conventional sampling-based methods, PVM, turbidity measurement, PDW spectroscopy, as well as FBRM and especially the combination of these different PAT may significantly leverage the development of new thermo-responsive material and the understanding of their transition processes.

Acknowledgments The authors would like to acknowledge the financial support from the German Federal Ministry of Education and Research (grant no. 03Z2AN12 and 03Z22AN12) and the German Federal country of Brandenburg (ERSD I\&II).

\section{Compliance with ethical standards}

Conflict of Interest The authors declare that they have no conflict of interest.

Open Access This article is distributed under the terms of the Creative Commons Attribution 4.0 International License (http:// creativecommons.org/licenses/by/4.0/), which permits unrestricted use, distribution, and reproduction in any medium, provided you give appropriate credit to the original author(s) and the source, provide a link to the Creative Commons license, and indicate if changes were made.

\section{References}

1. Otake K, Inomata H, Konno M, Saito S. Thermal analysis of the volume phase transition with $\mathrm{N}$-isopropylacrylamide gels. Macromolecules. 1990;23:283-9.

2. Kubota K, Fujishige S, Ando I. Single-chain transition of poly(Nisopropylacrylamide) in water. J Phys Chem-US. 1990;94:5154-8.

3. Kubota K, Hamano K, Kuwahara N, Fujishige S, Ando I. Characterization of $\operatorname{poly}(N$-isopropylmethacrylamide $)$ in water. Polym J. 1990;22:1051-7.

4. Wang X, Qiu X, Wu C. Comparison of the coil-to-globule and the globule-to-coil transitions of a single poly(N-isopropylacrylamide) homopolymer chain in water. Macromolecules. 1998;31:2972-6.

5. Wu XS, Hoffman AS, Yager P. Synthesis and characterization of thermally reversible macroporous poly $(N$-isopropylacrylamide $)$ hydrogels. J Polym Sci Polym Chem. 1992;30:2121-9. 
6. Schild HG. Poly(N-isopropylacrylamide): experiment, theory and application. Prog Polym Sci. 1992;17:163-249.

7. Huffman AS, Afrassiabi A, Dong LC. Thermally reversible hydrogels: II delivery and selective removal of substances from aqueous solutions. J Control Release. 1986;4:213-22.

8. Francis R, Baby DK, Kumar DS. Poly( $N$-isopropylacrylamide) hydrogel: effect of hydrophilicity on controlled release of ibuprofen at different pH. J Appl Polym Sci. 2012;124:5079-88.

9. Zhang XZ, Zhuo RX, Cui JZ, Zhang JT. A novel thermo-responsive drug delivery system with positive controlled release. Int J Pharm. 2002;235:43-50.

10. Park K, Qiu Y. Environment-sensitive hydrogels for drug delivery. Adv Drug Deliv Rev. 2001;53:321-39.

11. Secker C, Völke A, Tiersch B, Koetz J, Schlaad H. Thermo-induced aggregation and crystallization of block copolypeptoids in water. Macromolecules. 2016;49:979-85.

12. Wang KL, Burban JH, Cussler EL. Hydrogels as separation agents. Adv Polym Sci. 1993;110:67-79.

13. Kawaguchi H, Fujimoto K, Mizuhara Y. Hydrogel microspheres III temperature-dependent adsorption of proteins on poly-Nisopropylacrylamide hydrogel microspheres. Colloid Polym Sci. 1992;270:53-7.

14. Luo Q, Liu P, Guan Y, Zhang Y. Thermally induced phase transition of glucose-sensitive core-shell microgels. ACS Appl Mater Interfaces. 2010;2:760-7.

15. Lu Y, Proch S, Schrinner M, Drechsler M, Kempe R, Ballauff M. Thermosensitive core-shell microgel as a "nanoreactor" for catalytic active metal nanoparticles. J Mater Chem B. 2009;19:3955-61.

16. Ballauff M, Lu Y. "Smart" nanoparticles: preparation, characterization and applications. Polymer. 2001;48:1815-23.

17. Grinberg VY, Dubovik AS, Kuznetsov DV, Grinberg NV, Grosberg AY, Tanaka T. Studies of the thermal volume transition of poly $(\mathrm{N}-$ isopropylacrylamide) hydrogels by high-sensitivity differential scanning microcalorimetry. 2. Thermodynamic functions. Macromolecules. 2000;33:8685-92.

18. Suzuki D, Horigome K. Binary mixtures of cationic and anionic microgels. Langmuir. 2011;27:12368-74.

19. Hellweg T, Dewhurst CD, Eimer W, Kratz K. PNIPAM-copolystyrene core-shell microgels: structure, swelling behavior, and crystallization. Langmuir. 2004;20:4330-5.

20. Gao X, Cao Y, Song X, Zhang Z, Xiao C, He C, et al. pH- and thermo-responsive poly(N-isopropylacrylamide-co-acrylic acid derivative) copolymers and hydrogels with LCST dependent on $\mathrm{pH}$ and alkyl side groups. J Mater Chem B. 2013;1:5578-87.

21. Yin X, Hoffmann AS, Stayton PS. Poly(N-isopropylacrylamide-copropylacrylic acid) copolymers that respond sharply to temperature and $\mathrm{pH}$. Biomacromolecules. 2006;7:1381-5.

22. Zhang Q, Zha L, Ma J, Liang B. A novel route to prepare $\mathrm{pH}-$ and temperature-sensitive nanogels via a semibatch process. J Colloid Interface Sci. 2009;330:330-6.

23. Huang J, Wu XY. Effects of $\mathrm{pH}$, salt, surfactant and composition on phasetransition of Poly(NIPAm/MAA) nanoparticles. J Polym Sci Polym Chem. 1999;37:2667-76.

24. Hoare T, Pelton R. Functional group distributions in carboxylic acid containing poly( $\mathrm{N}$-isopropylacrylamide) microgels. Langmuir. 2004;20:2123-33.

25. Wu C, Zhou S. Laser light scattering study of the phase transition of poly(N-isopropylacrylamide) in water. 1 . Single. Macromolecules. 1995;28:8381-7.

26. Wu C, Wang X. Light-scattering study of coil-to-globule transition of a poly(N-isopropylacrylamide) chain in deuterated water. Macromolecules. 1999;32:4299-301.

27. Crowther HM, Saunders BR, Mears SJ, Cosgrove T, Vincent B, King SM, et al. Poly(NIPAM) microgel particle de-swelling: a light scattering and small-angle neutron scattering study. Colloids Surf A. $1999 ; 152: 327-33$.
28. Cheng H, Shen L, Wu C. LLS and FTIR studies on the hysteresis in association and dissociation of poly( $\mathrm{N}$-isopropylacrylamide) chains in water. Macromolecules. 2006;39:2325-9.

29. Percot A, Zhu XX, Lafleur M. A simple FTIR spectroscopic method for the determination of the lower critical solution temperature of N-Isopropylacrylamide copolymers and related hydrogels. J Polym Sci Polym Phys. 2000;38:907-15.

30. Lin SY, Chen KS, Liang RC. Thermal micro ATR/FT-IR spectroscopic system for quantitative study of the molecular structure of poly(N-isopropylacrylamide) in water. Polymer. 1999;40:2619-24.

31. Sun B, Lin Y, Wu P, Siesler HW. A FTIR and 2D-IR spectroscopic study on the microdynamics phase separation mechanism of the poly(N-isopropylacrylamide) aqueous solution. Macromolecules. 2008;41:1512-20.

32. Coleman MM, Skrovanek DJ, Painter PC. A simple method for determining the lower critical solution temperature of polymer blends using a raman spectrometer. Appl Spectrosc. 1984;38:448-50.

33. Winnik FM. Fluorescence studies of aqueous solutions of poly(Nisopropylacrylamide) below and above their LCST. Macromolecules. 1990;23:233-42.

34. Cho EC, Lee J, Cho K. Role of bound water and hydrophobic interaction in phase transition of poly(N-isopropylacrylamide) aqueous solution. Macromolecules. 2003;36:9929-34.

35. Tam KC, Wu XY, Pelton RH. Viscometry-a useful tool for studying conformational changes of poly( $\mathrm{N}$-isopropylacrylamide) in solutions. Polymer. 1992;33:436-8.

36. Kessler RW, Kessler W, Zilkuling-Rusch E. A critical summary of spectroscopic techniques and their robustness in industrial PAT applications. Chem Ing-Tech. 2016;88:1-13.

37. De Kanter M, Meyer-Kirschner J, Viell J, Mitsos A, Kather M, Pich A, et al. Enabling the measurement of particle sizes in stirred colloidal suspensions by embedding dynamic light scattering into an automated probe head. Measurement. 2016;80:92-8.

38. Bressel L, Hass R, Reich O. Particle sizing in highly turbid dispersions by photon density wave spectroscopy. J Quant Spectrosc Radiat Transf. 2013;126:122-9.

39. Tanguchi J, Murata H, Okamura Y. Analysis of aggregation and dispersion states of small particles in concentrated suspension by using diffused photon density wave spectroscopy. Colloids Surf B. 2010;76:137-44.

40. Cletus B, Künnemeyer R, Martinsen P, McGlone A, Jordan R. Characterizing liquid turbid media by frequency-domain photon-migration spectroscopy. J Biomed Opt. 2009. doi:10.1117/1.3119282.

41. Richter SM, Shinde RR, Balgi GV, Sevick-Muraca EM. Particle sizing using frequency domain photon migration. Part Part Syst Charact. 1998;15:9-15.

42. Hass R, Munzke D, Reich O. Inline-Partikelgrößenmesstechniken für Suspensionen und Emulsionen. Chem Ing-Tech. 2010;82:477-90.

43. Su W, Hao H, Glennon B, Barett M. Spontanous polymorphic nucleation of $\mathrm{D}^{-}$-Mannitol in aqueous solution monitored with raman spectroscopy and FBRM. Cryst Growth Des. 2013;13:5179-87.

44. Kail N, Marquardt W, Briesen H. Process analysis by means of focused beam reflectance measurements. Ind Eng Chem Res. 2009;48:2936-46.

45. Howard KS, Nagy ZK, Saha B, Robertson AL, Steele G. Combined PAT-solid state analytical approach for the detection and study of sodium benzoate hydrate. Org Process Res Dev. 2009;13:590-7.

46. Zhou B, Moment A, Cuff J, Schafer W, Orella C, Sirota E, et al. Process development and control with recent new FBRM, PVM, and IR. Org Process Res Dev. 2015;19:227-35.

47. Simone E, Saleemi A, Nagy Z. In situ monitoring of polymorphic transformations using a composite sensor array of raman, NIR, and ATR-UV/vis spectroscopy, FBRM, and PVM for an intelligent decision support system. Org Process Res Dev. 2015;19:167-77.

48. Abioye A, Chi G, Simone E, Nagy Z. Real-time monitoring of the mechanism of ibuprofen-cationic dextran crystanule formation 
using crystallization process informations system (CryPRINS). Int J Pharm. 2016;509:264-78.

49. Sadar MJ. Turbidity science. Technical Information Series Booklet No. 11; 1998.

50. Schmidt-Hager J, Ude C, Findeis M, John GT, Scheper T, Beutel S. Noninvasive online biomass detector system for cultivation in shake flasks. Eng Life Sci. 2014;14:467-76.

51. Hongve D, Åkesson G. Comparison of nephelometric turbidity measurements using wavelengths $400-600$ and $860 \mathrm{~nm}$. Water Res. 1998:32:3143-5.

52. Gooding Z, Pimenov K, Wang L, Asher S. UV resonance raman determination of molecular mechanism of poly(Nisopropylacrylamide) volume phase transition. J Phys Chem B. 2009;113:4248-56.

53. Hass R, Münzberg M, Bressel L, Reich O. Industrial applications of photon density wave spectroscopy for in-line particle sizing. Appl Opt. 2013;52:1423-31.

54. Hass R, Munzke D, Ruiz SV, Tippmann J, Reich O. Optical monitoring of chemical processes in turbid biogenic liquid dispersions by photon density wave spectroscopy. Anal Bioanal Chem. 2015;407:2791-802.

55. Ruiz SV, Hass R, Reich O. Optical monitoring of milk fat phase transition within homogenized fresh milk by photon density wave spectroscopy. Int Dairy J. 2012;26:120-6.

56. Fishkin J, Fantini S, vandeVen M, Gratton E. Gigahertz photon density waves in a turbid medium: theory and experiments. Phys Rev E. 1996;53:2307-19.

57. Münzberg M, Hass R, Khanh N, Reich O. Limitations of turbidity process probes and formazine as their calibration standard. Anal Bioanal Chem. 2016. doi:10.1007/s00216-016-9893-1.

58. Zhang B, Tang $\mathrm{H}$, Wu P. The unusual volume phase transition behavior of the poly(N-isopropylacrylamide)-poly(2hydroxyethyl methacrylate) interpenetrating polymer network microgel: different roles in different stages. Polym Chem. 2014;5:5967-77.

59. Gawlitza K, Turner ST, Polzer F, Wellert S, Karg M, Mulvaney P, et al. Interaction of gold nanoparticles with thermoresponsive microgels: influence of the cross-linked density on optical properties. Phys Chem Chem Phys. 2013;15:15623-31.

60. Zhu X, Gu X, Zhang L, Kong XZ. Preparation and characterization of nanosized P(NIPAM-MBA) hydrogel particles and absorption of bovine serum albumin on their surface. Nanoscale Res Lett. 2012;7: 519-26.

61. Hass R, Reich O. Photon density wave spectroscopy for dilutionfree sizing of highly concentrated nanoparticles during starved-feed polymerization. Chem Phys Chem. 2011;12:2572-5.

62. Hass R. Angewandte Photonendichtewellen Spektroskopie. Dissertation at the University Potsdam; 2011.

63. Kasarova SN, Sultanova NG, Ivanov CD, Nikolov ID. Analysis of dispersion of optical plastic materials. Opt Mater. 2007;29:148190.

64. Kholodovych V, Welsh W, Mark E. Physical properties of polymers handbook. 2nd ed. New York: Springer; 2007.

65. Burmistrova A, Richter M, Uzum C, Klitzing R. Effect of crosslinker density of P(NIPAM-co-AAc) microgels at solid surfaces on the swelling/shrinking behavior and the Young's modulus. Colloid Polym Sci. 2011;289:613-24.

66. Maeda Y, Higuchi T, Ikeda I. Change in Hydration state during the coil-globule transition of aqueous solution of poly $(\mathrm{N}-$ isopropylacrylamide) as evidenced by FTIR spectroscopy. Langmuir. 2000;16:7503-9.

67. Burmistrova A, Richter M, Isele M, Üzüm C, Klitzing R. The effect of co-monomer content on the swelling/shrinking and mechanical behaviour of individually adsorbed PNIPAM microgel particles. Polymers. 2011;3:1575-90.

68. Pelton R, Chibante P. Preparation of aqueous latices with $N$ isopropylacrylamide. Colloids Surf. 1986;20:247-56.

69. Snowden M, Vincent B. The temperature-controlled flocculation of crosslinked latex particles. J Chem Soc Chem Commun. 1992;16: 1103-5.

70. Rasmusson M, Routh A, Vincent B. Flocculation of microgel particles with sodium chloride and sodium polystyrene sulfonate as a function of temperature. Langmuir. 2004;20:353642 . 